\title{
Exploring the Relationship between Perceived Stress and Academic Achievement among Critical Care Nursing Students
}

\author{
By Samah Anwar Mohamed Shalaby* \\ Sara Mahdi Swaid AlDilh
}

\begin{abstract}
Critical care nursing students are prone to stressors during their academic and clinical experience which may interfere with their learning process. The aim of this study is to explore the stress level and stressors of critical care nursing students in King Saud Ben Abdulaziz University for Health Sciences, and to pinpoint the relationship between stress and academic achievement. Sixty nursing enrolled in Critical care nursing course students were included in the study. A self-reported questionnaire namely; developed by the researchers to explore the relationship between perceived stress and academic achievement. Sixty five percent of the respondents had low stress level, and $68.3 \%$ had multiple health problems during the

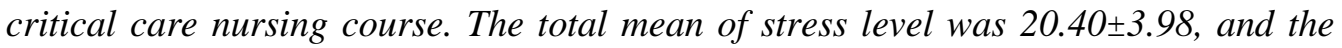
mean of perceived stressors was $61.23 \pm 17.84$. There was statistical significant difference between the stress level and perceived stressors where $p<0.001$ but there was no significant correlation between students' perceived stressors and academic achievement. Critical care nursing students experienced low to moderate stress level with no impact on their academic achievement.
\end{abstract}

Keywords: Academic achievement, Critical care nursing students, Stress, Stressors

\section{Introduction}

In an era of increasing competition in nursing field, nursing education is considered as one of the most crucial element for improving the quality of professional identity of future nurses. Nursing education in Saudi Arabia underwent dramatic change during the recent years as a result of increasing demand for highly qualified skillful nurses. Therefore, increasing the attention to nursing education and overcoming any obstacles which may affect the nursing learning process is a crucial goal for all academic nursing institutions (Hosseiny et al. 2005).

Stress among nursing students has been reported in several studies (Jimenez et al. 2010, Chan et al. 2009). Stress is the pattern of both specific and nonspecific responses that an organism makes to stimulus and/or events that disturb its equilibrium and exceed its ability to cope (Sharma et al. 2013). Stress has been identified as a twentieth century disease and has been viewed as either wear or tear that human bodies are going through such adjustment to continuously changing environment (Behere et al. 2011). Stress can be

\footnotetext{
* Lecturer Critical Care and Emergency, Faculty of Nursing, Alexandria University, Egypt.

${ }^{\dagger}$ Critical Care Nursing Student, College of Nursing, King Saud Bin Abdulaziz University for Health Sciences, Saudi Arabia.
} 
considered as both physical and emotional threat, in which the individual perceived a situation as a potential threat (Evans and Kelly 2004). A stressor can be viewed as a double-edged weapon which may stimulate and motivate the students to peak performance or reduce the students to ineffectiveness. Furthermore, perceived stressors can be physical, social, or psychological origin and subsequently affect the health outcomes (Glanz et al. 2008). For nursing students, clinical education is crucial and complex part of nursing education. However, it is also one of the main sources of stress for nursing students due to the factors students have to face in a critical care setting including the complexity of the technical tasks, advanced technology, the nature of critical illness, and needs of patients.

The relation between clinical nursing education and stress among students had been explored in several studies. According to Alzayyat and Al-Gamal (2014) and Khater et al. (2014), nursing students face a wide range of stressors related to their academic studies; tasks and assignments, grades, exams, and teachers; clinical training stressors due to their lack of experience, knowledge and clinical skills, and nursing staff (Sheu et al. 2002); as well as to external stressors as personal issues, day-to-day stressors. Most importantly, it was also found that stress related to lack of knowledge and skills was the highest sources of stress (Jimenez et al. 2010), and students also reported fear of being observed by the faculty during clinical training (Kim 2003).

Nursing students are immersed in the teaching-learning process in both theoretical and practical parts, which is very challenging in their academic experience and particularly significant for their professional preparation. Moreover, nursing students had general academic stressors similar to their colleagues in different colleges including; assignments, quizzes, midterm plus final semester examinations in addition to wide range of preparatory training before and during the clinical experiences (Sharma and Kaur 2011).

There are several factors which are considered stress provoking among nursing students include; academic and/or clinical challenges, technological advances, interpersonal difficulties, family or financial problems, physical and mental health issues, inadequate support, and poor coping skills (Cook 2005). Also they have to deal with cultural harmonization, language barrier, social isolation and discrimination (Junious et al. 2010).

Likewise, critical care nursing $(\mathrm{CCN})$ students encounter specific stressors in the new clinical rotation and these stressors include; implementation of technical skills, fear of facing life threatening events or situations in intensive care units, and the writing of care plans (Nolan and Ryan 2008). Also, they must deal with highly technical equipment, perform complex procedures which may cause serious harm to their critically ill patients in the distressing clinical settings, work with dying patient, and face inter and/ or intrapersonal conflict with other colleagues, feel of insecurity about clinical competences and fear of failure (Ratanasiripong and Wang 2011).

Numerous studies (Suliman and Halabi 2007, Kim 2003) suggested that several sources of stress during nursing education and training include; fear from unknown, new clinical environment, conflict between the ideal and real 
during the clinical practice, unfamiliarity with medical history, lack of professional nursing skills, unfamiliar patient' diagnosis and therapeutic modalities. Also the students' had to provide physiological, psychological and social care to critically ill patients with their fear of making mistakes or dying of terminally ill patients.

Others (Shipton 2002, Pulido et al. 2012) reported sources of stress among student nurses include; negative interaction with instructors, continuous observation by instructors and unpunctuality, poor relationships with hospital staff, and sometimes even talking with other health care providers. Moreover, stress in nursing students may arise from a combination of personal and extracurricular factors rather than from the educational program itself.

In the past decades, stress among CCN students has become an area of growing interest as it may result in psychological distress, physical complaints, behavioral problems and poor academic achievement. Some stressors among CCN students may be motivating, whereas too high levels interfere with learning process. Excessive and prolonged stress can be harmful to a student's academic achievement and may lead a student to drop out of college (Seyedfatemi et al. 2007).

Several studies (Khanehkeshi 2012, Watson et al. 2008) have shown that prolonged exposure to stress can be harmful to nursing student's academic performance or welfare also could interfere with learning a complex psychomotor skill (Khater et al. 2014). Moreover, stress could lead to serious health problems with a wide variety of both physiological and psychological symptoms such as; anxious, irritability, decreased concentration, digestion problems, eating disorders, frequent backache, headaches, mood swings, nervousness, tremors, and sleep disorders (Chipas et al. 2012, Jimenez et al. 2010).

Since, CCN students are more prone to a wide assortment of stressors during their theoretical and clinical experience which may interfere with their learning process. Also despite the growing literature on stress among nursing student internationally, apparently little can be found on the literature highlighting experiences of Saudi student nurses. Therefore, the current study aims to explore the stress level and stressors as perceived by $\mathrm{CCN}$ students, and pinpoint the relationship between stress and academic achievement.

\section{Methods}

Design

A descriptive correlation exploratory design was used to achieve the purpose of the current study. 
Vol. 2, No. $4 \quad$ Shalaby et al.: Exploring the Relationship between Perceived Stress...

Setting

The study was conducted at College of Nursing, King Saud Bin Abdulaziz University for Health Sciences, Jeddah, KSA.

\section{Study Participants}

A convenient sampling technique was used in the current study. The population of the study consisted of a total number of 60 female students who enrolled in CCN course in the academic year 2013-2014 at college of nursing, King Saud Bin Abdulaziz University for health sciences, Jeddah and consented to participate in the current study.

\section{Tools}

A self-reported structured questionnaire namely; Critical Care Nursing Students' Stress (CCNSS), was used to explore the stress level and stressors as perceived by $\mathrm{CCN}$ students. It consisted of three parts as the following:

- Part 1: It included the demographic characteristics of the respondent students such as age, educational level, and student's academic achievement includes; both CCN course and whole semester GPA, in addition to any health complains developed during their CCN course duration.

- Part 2: It comprised 10 items scale namely; perceived stress scale (PSS) and it was developed by Cohen et al. (Cohen et al. 1983) to assess CCN students' stress level with internal consistency reliability (Cronbach's $\alpha=0.85$ ). These items were rated on 5 point scale varied from 0 for never, 1 for almost never, 2 for sometimes, 3 for fairly often, and 4 for very often. The overall score ranged from $0-40$, with the higher scores indicating greater perceived stress. The total perceived stress score was the sum of the 10 items and some of the questions (4, $5,7, \& 8$ ) needed to reverse scored, as these questions were indications of positive ways of handling stress. The overall score of less than 10 indicated relatively stress free, 11-20 described low stress; 21-30 described moderate stress, and above 30 showed severe stress.

- Part 3: It included 38 items scale namely; perceived stressors (PS) which was developed by the researchers after reviewing related literatures (Sharma and Kaur, 2011, Watson et al. 2008, Khater et al. 2014, Chipas et al. 2012, Jimenez et al. 2010) to assess CCN students' perceived stressors. It was subdivided into 4 categories of potential sources of stress: 13 items for clinical, 9 items for academic activity, 9 items for intrapersonal and 7 items for interpersonal sources. All items were rated on a 4-point Likert scale varied from 0 for never stressful to 3 for always stressful. 
The questionnaire was tested for validity by asking five experts in $\mathrm{CCN}$ field for relevancy and necessary modifications were done. The Reliability was tested and Cronbach's alpha coefficient of part three was 0.95 .

The researcher distributed the structured questionnaire to the study participants who agreed to participate after asking them to sign the informed consent during their break time to ensure that they received standardized instructions on how to complete the questionnaire.

\section{Ethical and Legal Consideration}

The researcher submitted the research proposal and questionnaire to the Research Committees of the nursing college for review and an official permission for data collection was later granted by the committee. All the participants were informed about the background and objectives of the study. All respondents were required to indicate their willingness to participate in the study by signing a written informed consent and were informed of their right to withdraw from the study at any time. Confidentiality was ensured in the current study.

\section{Results}

The current study is concerned with exploring the stress level and stressors as perceived by CCN students in King Saud Ben Abdulaziz University for Health Sciences, and pinpoints the relationship between stress and academic achievement. Table 1 shows the distribution of CCN students according to their socio-demographic characteristics. It is clear that students' number were 60 and $55 \%$ of them were on stream one. Regarding nurses' age the Table 1 reveals that critical care nurses students' age ranged between 20 and 30 years, with the highest percentage $(81.7 \%)$ in the age group between 21 to 25 years. In relation to marital status the results demonstrate that $76.7 \%$ of the studied sample was single while $23.3 \%$ were married. Concerning students GPA in CCN course, $50 \%$ of students had GPA ranged from 3.5 to 4.49 , while other $50 \%$ of the students had had GPA ranged from 2 to 3.49. Regarding the students' residence $85 \%$ of had residence away from the college. Also $61.7 \%$ of the students had a transportation problem. Regarding the occurrence of health problems during the CCN course duration, it was found that $68.3 \%$ of students developed multiple health problems on the other hand only $26.7 \%$ of students had no health problem during the course. 
Vol. 2, No. $4 \quad$ Shalaby et al.: Exploring the Relationship between Perceived Stress...

Table 1. Distribution of CCN Students according to Socio-Demographic Characteristics $(N=60)$

\begin{tabular}{|c|c|c|}
\hline Socio-demographic Characteristics & $f$ & $\%$ \\
\hline $\begin{array}{cc}\text { Age: } & \\
- & 21-25 \text { years } \\
\bullet & 26-30 \text { years }\end{array}$ & $\begin{array}{l}49 \\
11\end{array}$ & $\begin{array}{l}81.7 \\
18.3\end{array}$ \\
\hline \begin{tabular}{cl}
\multicolumn{2}{l}{ Marital status: } \\
- & Single \\
- & Married \\
\end{tabular} & $\begin{array}{l}46 \\
14 \\
\end{array}$ & $\begin{array}{r}76.7 \\
23.3 \\
\end{array}$ \\
\hline \begin{tabular}{rr}
\multicolumn{2}{l}{ Stream: } \\
$\qquad \quad 1$ \\
$\bullet \quad 2$ \\
\end{tabular} & $\begin{array}{l}33 \\
27 \\
\end{array}$ & $\begin{array}{l}55 \\
45\end{array}$ \\
\hline $\begin{array}{cc}\text { CCN course GPA: } \\
\qquad \quad 3.5-4.49 \\
-\quad 2-3.49 \\
\end{array}$ & $\begin{array}{l}30 \\
30\end{array}$ & $\begin{array}{l}50 \\
50\end{array}$ \\
\hline $\begin{array}{l}\text { Residence: } \\
\text { - Away from college } \\
\text { - Near to college }\end{array}$ & $\begin{array}{c}51 \\
9\end{array}$ & $\begin{array}{l}85 \\
15\end{array}$ \\
\hline $\begin{array}{l}\text { Transportation problem: } \\
\text { - Yes } \\
\text { - No }\end{array}$ & $\begin{array}{l}37 \\
23 \\
\end{array}$ & $\begin{array}{l}61.7 \\
38.3\end{array}$ \\
\hline $\begin{array}{cl}\text { Health problems: } \\
\text { - } & \text { No } \\
\text { - } & \text { Single } \\
\text { - } & \text { Multiple }\end{array}$ & $\begin{array}{c}16 \\
3 \\
41 \\
\end{array}$ & $\begin{array}{c}26.7 \\
5 \\
68.3 \\
\end{array}$ \\
\hline
\end{tabular}

Source: Authors' estimations.

Table 2 shows the distribution of health problems as perceived by $\mathrm{CCN}$ students. The results revealed that $73.3 \%$ of students had health problems perceived as related to critical care course. The findings indicated that the most frequently reported ones were headache $(61.7 \%)$, fatigue and sleep disorders $(53.3 \%)$, eating disorders $(41.7 \%)$, decreased concentration $(40 \%)$, frequent back or neck pain (33.3\%), and anxiety and/or agitation $(25 \%)$. On the other hand less than quarter of the students developed health problems that include; mood swings, impatient with others, nervousness and/or tremors, and annoyed by trivial things. 
Table 2. Distribution of Health Problems as Perceived by CCN Students

\begin{tabular}{|c|c|c|}
\hline \multicolumn{1}{|c|}{ Health problems } & $\boldsymbol{f}$ & $\boldsymbol{\%}$ \\
\hline $\begin{array}{c}\text { Health problems: (N=60) } \\
\text { • Do not have health problem }\end{array}$ & 16 & 26.7 \\
• Have health problems & 44 & 73.3 \\
\hline Perceived health problems: $(\mathrm{N}=44)$ & & \\
\hline$\bullet \quad$ Anxiety and/or agitation & 15 & 25 \\
\hline$\bullet \quad$ Annoyed by trivial things & 8 & 13.3 \\
\hline$\bullet \quad$ Decreased concentration & 24 & 40 \\
\hline$\bullet \quad$ Digestion problem(GERD) & 18 & 30 \\
\hline$\bullet \quad$ Eating disorders & 25 & 41.7 \\
\hline$\bullet \quad$ Frequent back/neck pain & 20 & 33.3 \\
\hline$\bullet \quad$ Headache & 37 & 61.7 \\
\hline$\bullet \quad$ Impatient with others & 11 & 18.3 \\
\hline$\bullet \quad$ Mood swings & 14 & 23.3 \\
\hline$\bullet \quad$ Nervousness/tremors & 8 & 13.3 \\
\hline$\bullet \quad$ Fatigue & 32 & 53.3 \\
\hline$\bullet \quad$ Sleep disorders & & 53.3 \\
\hline
\end{tabular}

Note: $\quad *$ Significant values at $\mathrm{p} \leq 0.05$.

Source: Authors' estimations.

Table 3 shows students' scores on the perceived stress scale. It is clear that majority of students reported low to moderate level of stress. Whereas, $65 \%$ of students had low stress level and $28.3 \%$ of students had moderate level of stress. It can be seen also that the total score of perceived stress ranged between 14 and 34, with a mean score of $(20.40 \pm 3.98)$.

Table 3. Distribution of Students according to Their Stress Level Scores

\begin{tabular}{|c|c|c|c|c|c|c|}
\hline PSS & $f$ & $\%$ & Min & $\operatorname{Max}$ & Mean & $S D$ \\
\hline Stress free $<10$ & 0 & 0 & \multirow[b]{5}{*}{14} & \multirow[b]{5}{*}{34} & \multirow[b]{5}{*}{20.40} & \multirow[b]{5}{*}{3.98} \\
\hline Low stress 11- 20 & 39 & 65 & & & & \\
\hline Moderate stress 21- 30 & 17 & 28.3 & & & & \\
\hline High stress 31-40 & 4 & 6.7 & & & & \\
\hline Total & 60 & 100 & & & & \\
\hline
\end{tabular}

Source: Authors' estimations.

Table 4 shows students' scores on the perceived stressors scale. It is clear that majority of students reported that the stressors occurred frequently to always. Whereas, $65 \%$ of students reported that the stressors were frequent and $26.7 \%$ of students reported that the stressors were always. Also, it can be seen that the total score of perceived stressors ranged between 9 and 94, with a mean score of $(61.23 \pm 17.84)$. 
Vol. 2, No. $4 \quad$ Shalaby et al.: Exploring the Relationship between Perceived Stress...

Table 4. Distribution of Students according to their Perceived Stressors Scores

\begin{tabular}{|c|c|c|c|c|c|c|}
\hline Stressors category & f & $\%$ & Min & $\operatorname{Max}$ & Mean & SD \\
\hline Occasionally stressful $\leq 38$ & 5 & 8.3 & \multirow[b]{4}{*}{9} & \multirow[b]{4}{*}{94} & \multirow[b]{4}{*}{61.23} & \multirow[b]{4}{*}{$\mathbf{1 7 . 8 4}$} \\
\hline Frequently stressful 39-76 & 39 & 65 & & & & \\
\hline Always stressful 77-114 & 16 & 26.7 & & & & \\
\hline Total & 60 & 100 & & & & \\
\hline
\end{tabular}

Source: Authors' estimations.

Table 5 shows students' scores on the perceived stressor mean and its subscales. From the table, it is clear that students reported different degree of stress from different sources. The most common source of students' stress was clinical stressor as shown by the highest stress mean reported by the students $(20.65 \pm 5.69)$, followed by intrapersonal, and academic (15.12 \pm 6.68 , $14.32 \pm 5.22$, and $11.15 \pm 4.52$ respectively). The least reported perceived stressor was interpersonal (11.15 \pm 4.52$)$. In addition, the total score of nursing stress

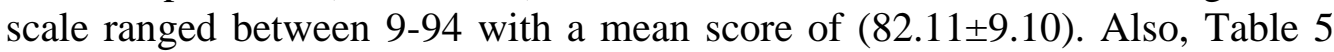
revealed that exist statistically significant difference between the perceived stressor means and its subscale $(\mathrm{t}=-23.985, \mathrm{p}<0.001, \mathrm{t}=-17.714, \mathrm{p}<0.001, \mathrm{t}=-$ $14.156, \mathrm{p}<0.001$, and $\mathrm{t}=-16.043, \mathrm{p}<0.001$ respectively).

Table 5. Students' Scores on the Perceived Stressor Mean and its Subscales

\begin{tabular}{|l|c|c|c|c|}
\hline \multicolumn{1}{|c|}{ PS subscales and their ranges } & Scores & Mean \pm SD & t & p \\
\hline Clinical stressors (0-39 points) & $1-32$ & $20.65 \pm 5.69$ & -23.985 & $<0.001^{*}$ \\
\hline Academic stressors (0-27 points) & $2-24$ & $14.32 \pm 5.22$ & -17.714 & $<0.001^{*}$ \\
\hline Intrapersonal stressors (0-27 points) & $0-27$ & $15.12 \pm 6.68$ & -14.156 & $<0.001^{*}$ \\
\hline Interpersonal stressors (0-21 points) & $1-20$ & $11.15 \pm 4.52$ & -16.043 & $<0.001^{*}$ \\
\hline
\end{tabular}

* Significant values at $\mathrm{p} \leq 0.05$

Source: Authors' estimations.

Table 6 shows nurses distribution according to their perception of the frequency of stressor subscales items. The results reveal that clinical stressor was the highest stressor seen as "frequently stressful" by $75 \%$, then intrapersonal stressors as "frequently stressful" by $55 \%$ of the sample, followed by interpersonal stressors were seen as "frequently stressful" by $51.7 \%$, and finally academic stressors were seen as "frequently stressful" by $48.3 \%$.

Table 6. Students Responses according to their Perception of Stressors Subscales

\begin{tabular}{|l|c|c|c|c|c|c|c|}
\hline \multicolumn{1}{|c|}{ PS subscales } & \multicolumn{2}{c|}{$\begin{array}{c}\text { Occasionally } \\
\text { stressful }\end{array}$} & \multicolumn{2}{c|}{$\begin{array}{c}\text { Frequently } \\
\text { stressful }\end{array}$} & \multicolumn{2}{c|}{ Always } & Mean \pm SD \\
\hline & $\boldsymbol{f}$ & $\mathbf{\%}$ & $\boldsymbol{f}$ & $\mathbf{\%}$ & $\boldsymbol{f}$ & $\mathbf{\%}$ & \\
\hline Clinical stressors & 7 & 11.7 & 45 & 75 & 8 & 13.3 & $1.58 \pm 0.43$ \\
\hline Academic stressors & 16 & 26.7 & 29 & 48.3 & 15 & 25 & $1.59 \pm 0.57$ \\
\hline Intrapersonal stressors & 14 & 23.3 & 33 & 55 & 13 & 21.7 & $1.68+0.74$ \\
\hline Interpersonal stressors & 16 & 26.7 & 31 & 51.7 & 13 & 21.7 & $1.59+0.65$ \\
\hline
\end{tabular}

Source: Authors' estimations. 
Table 7 exhibits correlations between students' level of stress and their associated stressors. The total level of stress was significantly positively correlated with their perceived stressors $(\mathrm{p}=0.005)$.

Table 7. Correlations Between Students' Degree of Stress and their Stressors

\begin{tabular}{|c|c|c|c|c|c|}
\hline \multirow[b]{2}{*}{ Stress levels } & \multicolumn{4}{|c|}{ Perceived stressors } & \\
\hline & $\begin{array}{c}\text { Occasionally } \\
\text { stressful }\end{array}$ & $\begin{array}{c}\text { Frequently } \\
\text { stressful }\end{array}$ & $\begin{array}{c}\text { Always } \\
\text { stressful }\end{array}$ & Total & $\begin{array}{c}\text { Chi-Square } \\
\text { Tests }\end{array}$ \\
\hline Low stress & 5 & 25 & 9 & 39 & \\
\hline Moderate stress & 0 & 14 & 3 & 17 & \\
\hline High stress & 0 & 0 & 4 & 4 & \\
\hline Total & 5 & 39 & 16 & 60 & $0.005 *$ \\
\hline
\end{tabular}

* Significant values at $\mathrm{p} \leq 0.05$

Source: Authors' estimations.

Table 8 exhibits correlation between the mean students' stress level and stressors as there was a statistically significant difference between the total students' stress level and their perceived stressor where; $(\mathrm{t}=-18.652, \mathrm{p}<0.001)$.

On the other hand, no statistical significant difference was found between students' stress level and their critical care GPA ( $\mathrm{F}=1.533, \mathrm{p}=0.221)$. Also, no statistical significant difference was found between students' stressors scores and their critical care GPA ( $\mathrm{F}=0.701, \mathrm{p}=0.406)$.

Table 8. Correlation Between Mean of Students' Level of Stress and their Stressors

\begin{tabular}{|l|c|c|}
\hline & $\mathbf{t}$ & $\mathbf{p}$ \\
\hline Students' stress level score and perceived stressors & -18.652 & $0.001^{*}$ \\
\hline
\end{tabular}

Source: Authors' estimations.

Table 9 shows the relation between students' socio-demographic characteristics and their levels of stress. From Table 9 it can be seen that, a statistical significant difference was found between students' stress level and their marital status and health problems where $(\mathrm{p}=0.037$, and $\mathrm{p}=0.047$ respectively), while no statistical significant difference was found between students' stress level and their age and GPA at the critical care course. 
Vol. 2, No. $4 \quad$ Shalaby et al.: Exploring the Relationship between Perceived Stress...

Table 9. Correlations Between Students' Socio-Demographic Characteristics and their Stress Level

\begin{tabular}{|c|c|c|c|c|}
\hline Socio-demographic & Low stress & Moderate stress & High stress & Chi-Square \\
\hline $\begin{array}{l}\text { Age: } \\
\quad \text { - } 21-25 \text { years } \\
\text { - } 26-30 \text { years }\end{array}$ & $\begin{array}{c}32(53.3 \%) \\
7(11.7 \%)\end{array}$ & $\begin{array}{c}13(21.6 \%) \\
4(6.7 \%)\end{array}$ & $\begin{array}{c}4(6.7 \%) \\
0(0 \%)\end{array}$ & 0.547 \\
\hline $\begin{array}{l}\text { Marital status: } \\
\text { - } \quad \text { Single } \\
\text { - } \quad \text { Married } \\
\end{array}$ & $\begin{array}{c}32(53.3 \%) \\
7(11.7 \%)\end{array}$ & $\begin{array}{c}13(21.7 \%) \\
4(6.7 \%) \\
\end{array}$ & $\begin{array}{c}1(1.6 \%) \\
3(5 \%) \\
\end{array}$ & $0.037 *$ \\
\hline $\begin{aligned} & \text { CCN GPA: } \\
& \bullet 3.5-4.49 \\
& \bullet 2-3.49 \\
&\end{aligned}$ & $\begin{array}{l}20(33.3 \%) \\
19(31.7 \%)\end{array}$ & $\begin{array}{c}10(16.7 \%) \\
7(11.7 \%)\end{array}$ & $\begin{array}{c}0(0 \%) \\
4(6.7 \%)\end{array}$ & 0.103 \\
\hline $\begin{array}{l}\text { Health problems: } \\
\text { - No } \\
\text { - Single } \\
\text { - Multiple }\end{array}$ & $\begin{array}{l}7(11.7 \%) \\
2(3.3 \%) \\
30(50 \%) \\
\end{array}$ & $\begin{array}{l}9(15 \%) \\
1(1.6 \%) \\
7(11.7 \%) \\
\end{array}$ & $\begin{array}{c}0(0 \%) \\
0(0 \%) \\
4(6.7 \%)\end{array}$ & $0.047 *$ \\
\hline
\end{tabular}

* Significant values at $\mathrm{p} \leq 0.05$

Source: Authors' estimations.

Table 10 shows the relation between students' socio-demographic characteristics and their perceived stressors. We notice that no statistical significant difference was found between students' perceived stressors and their age, marital status, health problems and GPA at the critical care course.

Table 10. Correlations Between Students' Socio-Demographic Characteristics and their Stressors

\begin{tabular}{|c|c|c|c|c|}
\hline Sociodemographic & $\begin{array}{c}\text { Occasionally } \\
\text { stressful }\end{array}$ & $\begin{array}{c}\text { Frequently } \\
\text { stressful }\end{array}$ & $\begin{array}{c}\text { Always } \\
\text { stressful }\end{array}$ & $\begin{array}{c}\text { Chi- } \\
\text { Square }\end{array}$ \\
\hline $\begin{array}{l}\text { Age: } \\
\text { - } 21-25 \text { years } \\
\text { - } 26-30 \text { years }\end{array}$ & $\begin{array}{l}4(6.7 \%) \\
1(1.6 \%)\end{array}$ & $\begin{array}{c}32(53.3 \%) \\
7(11.7 \%)\end{array}$ & $\begin{array}{c}13(21.6 \%) \\
3(5 \%)\end{array}$ & 0.993 \\
\hline $\begin{array}{l}\text { Marital status: } \\
\text { - } \quad \text { Single } \\
\text { - } \quad \text { Married } \\
\end{array}$ & $\begin{array}{l}4(6.7 \%) \\
1(1.6 \%)\end{array}$ & $\begin{array}{c}30(50 \%) \\
9(15 \%)\end{array}$ & $\begin{array}{l}12(20 \%) \\
4(6.7 \%)\end{array}$ & 0.972 \\
\hline 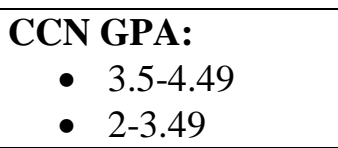 & $\begin{array}{l}4(6.7 \%) \\
1(1.6 \%)\end{array}$ & $\begin{array}{l}18(30 \%) \\
21(35 \%)\end{array}$ & $\begin{array}{l}8(13.3 \%) \\
8(13.3 \%)\end{array}$ & 0.362 \\
\hline $\begin{array}{l}\text { Health problems: } \\
\text { - No } \\
\text { - Single } \\
\text { - Multiple }\end{array}$ & $\begin{array}{c}4(6.7 \%) \\
0(0 \%) \\
1(1.6 \%)\end{array}$ & $\begin{array}{c}10 \\
2(3.3 \%) \\
27(45 \%)\end{array}$ & $\begin{array}{c}2(3.3 \%) \\
1(1.6 \%) \\
13(21.6 \%) \\
\end{array}$ & 0.062 \\
\hline
\end{tabular}

Source: Authors' estimations.

\section{Discussion}

Apparently the CCN students face unusual high levels of stress during their learning process, particularly related to their clinical duties, theoretical 
assignments, rapidly changing circumstances, in addition to interpersonal and intrapersonal conflict (Sharma and Kaur 2011, Cook 2005, Junious et al. 2010). Also their clinical training settings enforce them to deal with advanced technology, complex procedures and dying patients (Shipton 2002, ChesserSmyth 2005). CCN students are seldom aware with such stress which necessitates the understanding of the nature and level of stress experienced by them during $\mathrm{CCN}$ course as well as exploring their stress associated factors for effective learning process (Nolan and Ryan 2008, Ratanasiripong and Wang 2011, Changiz et al. 2012).

Stress level in this study was measured specifically by the scores reported by CCN students on the Perceived Stress Scale (PSS). The most important finding of the current study was that about two thirds of the students' stress levels were low. This appears to be contradicted with Papazisis et al. (2008) who found that nearly three quarters of nursing students in Greece perceived stress, most of them had mild levels while only $12.4 \%$ perceived very high levels of stress. Also against what Amr et al. (2011) reported that more than one third of nursing students perceived high stress level. Moreover, Singh et al. (2011) supported Labrague (2013) findings that the stress level among nursing students ranged from moderate to high levels.

The most astonishing finding was that almost three quarters of the students developed health problems perceived as related to CCN course. Whenever, more than half of them experienced headache, fatigue and sleep disorders. On the other hand, about one third of studied sample developed eating disorders, decreased concentration, and frequent back or neck pain which may be related to physio-psycho-social response to stress. This appears to be congruent with Chipas et al. (2012) findings in a study about stress among the student nurse anesthetists population at the Medical University of South Carolina.

Since clinical training is considered to be the core of nursing education and basically focused on providing direct patient care with often dramatic efforts to preserve life in coordination with improving the critical thinking and problem solving abilities of students. Therefore, it was not surprising that clinical stressors were ranked higher than the theoretical stressors among CCN students. This appears to be congruent with their clinical learning environment and is supported by many studies (Changiz et al. 2012, Chan et al. 2009, Keighobady et al. 2001, Gorostidi et al. 2007). On the other hand, this appears to be contradicted with Evans and Kelly (2004), who reported that the academic work load is the first and most important source of stress.

Furthermore, the current study revealed that the second source of stress was intrapersonal related, which perceived by more than half of students and encompasses; changes in eating or sleeping pattern, homesickness inside the hostel, new responsibilities or personal preoccupations, declining in general health, parents over expectations, death of significant one and finally economic or financial problems. Similar results were shown in the study conducted by Sharma et al. (2013).

Not surprisingly, results of this study showed that no correlation between the students stress level and their academic achievement which may be 
rationalized by either they did not perceive their stressors or they had coping mechanisms which are not assesses throughout the current study. This is congruent with the results of Abdulghani et al. (2011) and Hamaideh (2011) who reported that stress did not significantly correlated with academic achievement.

Moreover, positive associations were found between both marital status and health problems incidence in relation to stress level among the students as predicted and supported by higher intrapersonal stressors perception. This result was contradicting the findings of Rajesh (2011) who found that the socio-demographic data did not have any association with the stress level among nursing students.

\section{Conclusions - Recommendations}

Based on the current study findings, it can be concluded that despite the CCN students in King Saud Ben Abdulaziz University for Health Sciences perceived low stress level, they were exposed to a variety of clinical, intra and inter personal and theoretical stressors. Clinical experience and duties were the highest rank perceived by these students and may interfere with their physiopschyo-social wellbeing and academic performance. Therefore, clinical and academic staff together with college administrators must incorporate the stress management training into students' orientation. In addition to enhance the application of stress management, assertiveness skills, time management and counseling sessions to handle the stress experienced by nursing students. Finally there was no impact on the students' academic achievement. Therefore replication of the current study using qualitative design on a longitudinal base to identify their specific stressors and coping strategies related to $\mathrm{CCN}$ course.

\section{References}

Abdulghani H, AlKanhal A, Mahmoud E, Ponnamperuma G (2011) Stress and Its Effects on Medical Students: A Cross-sectional Study at a College of Medicine in Saudi Arabia. Journal of Health Population and Nutrition 29(5): 516-522.

Alzayyat A, Al-Gamal E (2014). A review of the literature regarding stress among nursing students during their clinical education. International Nursing Review 61: 406-415.

Amr M, El-Gilany A, El-Moafee H, Salama L, Jimenez C (2011) Stress among Mansoura (Egypt) baccalaureate nursing students. Pan African Medical Journal $8(26)$.

Behere SP, Yadav R, Behere PB (2011) A comparative study of stress among students of medicine, engineering, and nursing. Indian Journal of Physiological Medicine 33(2): 145-148.

Chan CK, So WK, Fong DY (2009) Hong Kong baccalaureate nursing students' stress and their coping strategies in clinical practice. Journal of Professional Nursing 25(5): 307-313. 
Changiz T, Malekpour A, Zargham-Boroujeni A (2012) Stressors in clinical nursing education in Iran: A systematic review. Iranian Journal of Nursing and Midwifery Research 17(6): 399-407.

Chesser-Smyth P (2005) The lived experiences of general student nurses on their first clinical placement: a phenomenological study. Nurse Education in Practice 5(6): 320-327.

Chipas A, Cordrey D, Floyd D, Grubbs L, Miller S, Tyre B (2012) Stress: Perceptions, Manifestations, and Coping Mechanisms of Student Registered Nurse Anesthetists. AANA Journal 80(4): S49-S55.

Cohen S, Kamarck T, Mermelstein R (1983) A global measure of perceived stress. Journal of Health and Social Behavior 24: 386-396.

Cook LJ (2005) Inviting teaching behaviors of clinical faculty and nursing students' anxiety. Journal of Nursing Education 44(4): 156-161.

Evans W, Kelly B (2004) Pre-registration diploma student nurse stress and coping measures. Nurse Education Today 24(6): 473-482.

Glanz K, Rimer B, Viswanath K (2008) Health Behavior and Health Education: Theory, Research and Practice ( $4^{\text {th }}$ edn.). San Francisco: Jossey Bass, p. 210-236.

Gorostidi X, Egilogor X, Erice M (2007) Stress sources in nursing practice. Evolution during nursing training. Nurse Education Today 27: 777-787.

Hamaideh S (2011) Stressors and reactions to stressors among university students. International Journal of Social Psychology 57(1): 69-80.

Hosseiny N, Karimi Z, Malek J (2005) The Situation of Clinical Education Based on Nursing Students' Opinion in Yasuj Nursing and Midwifery School. Iranian Journal of Medical Education 5: 171-175.

Jimenez C, Navia-Osorio P, Diaz C (2010) Stress and health in novice and experienced nursing students. Journal of Advanced Nursing 66(2): 442-455.

Junious D, Malecha A, Tart K, Young A (2010) Stress and perceived faculty support among foreign-born baccalaureate nursing students. Journal of Nursing Education 49(5): 261-270.

Keighobady S, Salemi S, Rasadi M, Mahmoodi M (2001) Degree of stress of clinical nursing stressors. Iranian Journal of Nursing 14: 19-24.

Khanehkeshi A (2012) The relationship of academic stress, depression, and selfefficacy with academic performance among high school students in Iran. Indian Streams Research Journal 1(4): 1-4.

Khater W, Akhu-Zaheya L, Shaban I (2014) Sources of Stress and Coping Behaviours in Clinical Practice among Baccalaureate Nursing Students. International Journal of Humanities and Social Science 4(6): 194-202.

Kim KH (2003) Baccalaureate nursing students' experiences of anxiety producing situations in the clinical setting. Contemporary Nurse 14(2): 145-155.

Labrague L (2013) Stress, Stressors, and Stress Responses of Student Nurses in a Government Nursing School. Health Science Journal 7(4): 424-435.

Nolan G, Ryan D (2008) Experience of stress in psychiatric nursing students in Ireland. Nursing Standard 22(43): 35-43.

Papazisis G, Vlasiadis I, Nektarios N, Tsiga E, Krepia D (2008) Depression and anxiety among nursing students in Greece. Annals of General Psychiatry 7(S1): S209.

Pulido M, Augusto J, Lopez E (2012) Sources of stress in nursing students: a systematic review of quantitative studies International Nursing Review 59: 15-25.

Rajesh N (2011) Stress and Coping Strategies among Nursing Students. Nursing and Midwifery Research Journal 7(4): 141-151. 
Ratanasiripong P, Wang C (2011) Psychological wellbeing of Thai nursing students. Nurse Education Today 31(4): 412-416.

Seyedfatemi N, Tafreshi M, Hagani H (2007) Experienced stressors and coping strategies among Iranian nursing students. BMC Nursing 6: 11-20.

Sharma B, Prasad S, Pandey R, Singh J, Sohdi KS, Wadhwa D (2013) Evaluation of Stress among Post-graduate Medical and Dental Students: A pilot study. Delhi Psychiatry Journal 16(2): 312-316.

Sharma N, Kaur A (2011) Factors associated with stress among nursing students. Nursing and Midwifery Research Journal 7(1): 12-21.

Sheu S, Lin H, Hwang S (2002) Perceived stress and physio-psycho-social status of nursing students during their initial period of clinical practice: the effect of coping behaviors. International Journal of Nursing Studies 39(2): 165-175.

Shipton SP (2002) The process of seeking stress-care: coping as experienced by senior baccalaureate nursing students in response to appraised clinical stress. Journal of Nursing Education 41(6): 243-256.

Singh C, Sharma S, Sharma R (2011) Level of stress and coping strategies used by nursing interns. Nursing and Midwifery Research Journal 7(4): 152-160.

Suliman W, Halabi J (2007) Critical thinking, self-esteem and state anxiety of nursing students. Nurse Education Today 27(2): 162-168.

Watson R, Deary I, Thompson D, Li G (2008) A study of stress and burnout in nursing students in Hong Kong: A questionnaire survey. International Journal of Nursing Studies 45(10): 1534-1542. 